\title{
Finding Space for the Truth: Joshua Cohen on Truth and Public Reason
}

\author{
Jethro Butler ${ }^{1}$ (D)
}

Published online: 23 September 2016

(C) The Author(s) 2016. This article is published with open access at Springerlink.com

\begin{abstract}
One of the most distinctive and startling claims of Rawlsian political liberalism is that truth has no place in public political deliberation on matters of basic justice. Joshua Cohen thinks there is a tension between Rawls's exclusion of truth in public political deliberation and the importance accorded to truth in the conception of morally serious political deliberation held by most citizens. Cohen claims that this apparent tension can be resolved by constructing and introducing a suitably political, non-divisive and neutral, conception of truth which is capable of satisfying both the highly distinctive requirements of Rawlsian political liberalism and the importance accorded to truth by the conception of public deliberation held by most citizens. In this paper I argue that Cohen is unsuccessful in this attempt and that his political conception of truth cannot satisfy both political liberalism and a descriptively adequate specification of the importance accorded to truth by the familiar accounts of morally serious political deliberation upon which Cohen relies.
\end{abstract}

Keywords John Rawls · Joshua Cohen · Deliberation · Truth · Public reason · Reasonableness · Descriptive adequacy

\section{Introduction}

John Rawls's claim that we do not need the concept of truth in order to elucidate a distinctively political liberalism and that, in a well ordered society, the concept of truth is unavailable to citizens and their representatives when deliberating on matters of basic justice is one of the most startling and original features of his work. Rawls's seemingly revisionary claim that truth can be eliminated from public

Jethro Butler

Jethro.Butler@warwick.ac.uk

1 Department of Politics and International Studies (PAIS), University of Warwick,

Coventry CV4 7AL, UK 
deliberation has come under sustained criticism as well as attracting some rather novel and elaborate defences. ${ }^{1}$ What most contributions to the debate have in common is a commitment to the claim that there is a basic incompatibility between the concept of truth and the idea of public reason. The deliberative democrat Joshua Cohen, on the other hand, attempts to find a middle way through this debate and he advances a highly interesting and sophisticated argument in support of the idea that public reason is capable of accommodating the concept of truth without requiring serious revision of the ideal of political liberalism and defending the compatibilist line that we can have both truth and public reason (Cohen 2009). ${ }^{2}$ I think that Cohen's attempt, sophisticated though it is, does not succeed in demonstrating the required compatibility. I also argue that, whereas he is able to show that his political conception of truth is consistent with political liberalism, he cannot at the same time make his conception of truth consistent with his own description of the folk understanding of public deliberation held by reasonable citizens; specifically, that arriving at the truth is to some extent the aim of deliberation.

\section{Deliberation and Descriptive Adequacy}

In this paper I am concerned with the concepts appropriate to a normative account of political deliberation about matters of justice and right characteristic of modern liberal democratic societies. How should the concept of truth feature in our normative account of such deliberation? If we are trying to come up with a convincing and persuasive normative account of the procedures of political deliberation about matters of justice and right what sort of considerations might we want to build into this account? One sort of question that presents itself immediately is just how far we can distance ourselves from the messy and diverse everyday practices and folk understanding of practical deliberation. We could, in designing our normative account of ideal deliberation, ignore all of this messiness and diversity and construct an account which has different and more consistent aims and norms. In this case we would end up with a highly revisionary account of deliberation and practical reason. On the other hand, we could attempt to model our account of deliberation and practical reason carefully on the everyday practices of deliberation in which case we would have a highly descriptive account of deliberation and practical reason. ${ }^{3}$ Our deliberative practices are a rich source of

\footnotetext{
${ }^{1}$ One side in this debate is characterised by the view that either political liberalism and/or public reason is untenable, at least without some major revision, precisely because these ideals cannot accommodate the concept of truth. For example see Joseph Raz (1994, 1998). The other side of this debate comprises arguments defending the Rawlsian line that political liberalism and public reason can do very well without the concept of truth, see Freeman (2003), or defending the line that public reason itself can do without the concept of truth just so long as truth makes an appearance in the justification of the political liberalism of which public reason is a part, see Estlund (1998). I would like to thank Richard North and the late, and much missed, Steve Buckler for helpful and insightful comments on earlier drafts of this paper.

2 A very brief statement of the view that truth can feature in a largely neutral fashion in political argument can also be found in (Cohen 1997, p. 96).

3 I am here using 'revisionary' and 'descriptive' in a way analogous to Peter Strawson's account of descriptive and revisionary metaphysics (Strawson 1959, pp. 9-12).
} 
basic data for such an account and it would be quite odd to regard these practices as wholly mistaken. However, the sheer diversity, messiness and complexity of our deliberative practices presents us with a number of problems.

Given that the world is messy and our practices of deliberation are varied, a descriptive account of deliberation and practical reason will also be messy and the analysis will be unlikely to achieve fully consistent explanatory principles with global scope. To be sure, the analysis will not be as messy as the practices themselves since it ought to untangle some of the knots, shine light in the obscure corners, make distinctions and draw useful parallels; but it will be a piecemeal effort at clarification. Our revisionary theorist, on the other hand, will strive towards neatness and explanatory principles of global scope. Unfettered by the requirement to reflect the messiness of the practices of deliberation the theory can aim for absolute consistency and we can feel free to make suggestions for reforming the practices of deliberation without fear that our theory is vulnerable to all of that complexity, diversity and mess. ${ }^{4}$

In reality the choice is not quite as stark or simple as this picture suggests. No plausible theory of deliberation would be purely descriptive and few would be so bold as to claim that their theory was entirely invulnerable to real-world diversity and complexity. However, the distinction between descriptive and revisionary theories is a useful one for our purposes if we regard it as a continuum upon which we can place theories according to whether they are more or less descriptive or more or less revisionary. So we could say of Aristotelian theories of practical reason and deliberation that they are very much on the descriptive end of the continuum, and of certain utilitarian theories that they are very much on the revisionary end of the continuum. As in so much else, the Rawlsian theory of deliberation strives for a middle way between these extremes. On the one hand, a desire for theoretical consistency pushes the Rawlsian theory of deliberation towards the revisionary end of the continuum. On the other, the requirement that the theory is congruent with the substantial and reasonable commitments of citizens, including their everyday deliberative practices, pushes it in the direction of description. There are clearly tensions created by the desire to reconcile these considerations. Are these tensions irreconcilable? That they are will be one of the conclusions of this paper.

However, before jumping the gun to that conclusion it is worth considering precisely what it would take to allow a theory of public deliberation to occupy the middle ground. For one thing we will need to show that the otherwise revisionary theory is able to satisfy some kind of test of descriptive adequacy. We will have to show that our theory, while having some revisionary features, can accommodate those elements of what I shall call an everyday folk deliberative conception that citizens possess and use in their ordinary deliberations. I will, for the purposes of this paper, call the requirement to accommodate the folk deliberative conception the descriptive adequacy condition for public deliberation (hereafter the DAC). ${ }^{5}$ Joshua

\footnotetext{
${ }^{4}$ G. A. Cohen presents a persuasive, albeit rather brief, defence of the messy and piecemeal conception of philosophical analysis (Cohen 2008, pp. 3-6).

5 There are a number of ways of setting up the descriptive adequacy condition. Joshua Cohen's interpretation of the condition comprises his 'five claims about truth' that I discuss in the following section.
} 
Cohen argues that Rawls's theory of deliberation does not satisfy the DAC since truth is an ineliminable feature of the folk deliberative conception. For this reason the Rawlsian theory of public deliberation is rather more revisionary than Rawls claims.

Joshua Cohen is motivated to deny that political liberalism and public reason can get along without truth because of three basic concerns about Rawls's truthexclusionary conception of public reason. Firstly, he thinks that the exclusion of truth is puzzling given that public reason appeals to the validity and soundness of arguments to govern the relevance of beliefs, assertions and judgements and that the appeal to the logical validity of arguments makes little sense if divorced from the idea that a valid argument is truth-preserving. Let us call this the 'mundane role of truth' in practical reason. ${ }^{6}$ Secondly, he thinks that the exclusion of truth makes it look as if political liberals do not take 'truthfulness' seriously (where 'truthfulness' is characterised by the virtues of seriousness and sincerity). Let us call this the 'culture of truthfulness'. Finally, the appearance of not caring about truthfulness undermines the case for saying that political liberals take 'getting it right' about justice seriously. Let us call this 'truth as the aim of deliberation': truth is the aim of deliberation insofar as citizens are concerned that they are 'getting it right' in their deliberations. Citizens care about truth and truthfulness in politics. If we want to avoid the charge of proposing an excessively revisionary theory of political deliberation then we have to accommodate this concern.

So, in order to satisfy the DAC our account of public reason has to accommodate 'mundane truth', 'the culture of truthfulness' and 'truth as the aim of deliberation'. Rawls's truth-exclusionary public reason is problematic since it appears to commit citizens to a joint exercise of practical reason which has a radical and highly revisionary character and is fundamentally at odds with the standards of deliberation that they ordinarily employ. The Rawlsian conception of public reason has the appearance of asking citizens to employ standards of deliberation that are fundamentally alien to their own.

Cohen thinks that deliberative democrats can avoid these problems since it is possible to construct a suitably political conception of truth which is neutral between the contending parties in the deeper metaphysical disputes about the concept of truth. This conception of truth, it is claimed, has the ability to capture the features of the various employments of the concept sufficiently well to allay the motivating concerns about the elimination of truth without forcing any substantial changes on the basic Rawlsian content of public reasoning. Although Cohen's argument is highly sophisticated I think that ultimately this attempt to accommodate truth in public reason is unpersuasive. In the first section of the paper I take a closer look at the Rawlsian argument for truth exclusion and precisely how Cohen sets up the political conception of truth and how he defends it against objections that he thinks might be ranged against it from the point of view of a truth-exclusionary conception of public reason. In the second section I explore a number of objections to the political conception of truth and its sufficiency for allaying his quite

\footnotetext{
${ }^{6}$ Jonathan Quong describes this as the 'mundane role of truth' (Quong 2011).
} 
legitimate concerns about the elimination of truth. I argue that Cohen's worries about truth are compelling but that his argument also fails to satisfy the DAC.

\section{The Problem of Truth}

Rawls has a number of reasons for wanting to eliminate the concept of truth from public reason. He is concerned to avoid the sort of commitment to a metaphysically substantial theory of truth which would drag political liberalism into matters of deep and intractable philosophical controversy. He also believes that controversy over the metaphysics of truth can be safely eliminated since the conceptual analysis of truth does not have any traction in matters of normative importance so these controversies can be avoided at little cost. More significantly, in a well-ordered society many individual citizens will be committed to deep metaphysical theories of truth and to strong and often exclusive claims about the truth of the goodness of the ways of life sanctioned by their reasonable comprehensive conceptions of the good. So, just so long as there is more than one distinct, committed and exclusive viewpoint about the good life, there will be controversy over substantial truths and which views about the good life (and ways of life less worthy) are ultimately true. There will also be a certain amount of controversy over the appropriate standards for assessing these conflicting views and the standards of reason appropriate to the discovery of these truths. The idea that perfectly reasonable and rational citizens can faultlessly disagree over these matters grounds an argument in favour of a restrictive ideal of public reasonableness.

Both Rawls and Cohen use this idea in order to claim, in effect, that every citizen has a moral right to be addressed by, and to deliberate upon, only reasons that all reasonable citizens could accept. Cohen adduces three Rawlsian arguments in support of the priority of reasonableness that grounds this right. The first (the argument from democratic equality) relies on the idea that the democratic ideal requires that all citizens are treated as free equals. If political authority is exercised over citizens for reasons that they could not accept then they are not treated as equals; they are treated as inferiors. Second, (the argument from the burdens of judgement) if we accept that citizens can reasonably disagree without epistemic fault about the deep content of their comprehensive doctrines then asserting justificatory reasons derived from what they believe to be the whole truth about these doctrines does not add anything to the force of the justification beyond the fact that these citizens happen to believe that their doctrine is true (and that reason has no force for any citizen who does not happen to believe in the truth of that doctrine). Third, (the argument from the two moral powers) if we are to respect people and their reasonable and rational capacity to order their lives as they see fit we ought not to compel them to live in ways contrary to their professed reasonable comprehensive commitments. This argument is grounded by accepting the burdens of judgement and accepting both that citizens may faultlessly disagree about comprehensive goods and that such disagreement is the natural result of people reasoning about the comprehensive good under institutions that enable them to do so freely. We must assume, so the argument goes, if we are reasonable and if we think 
our interlocutors are reasonable, that these others hold their commitments for what they take to be good reasons and that they are exercising their rational and reasonable capacities. Therefore, if we are to respect them we ought not to try and compel them for reasons they could not accept (even if we think their commitments are not justified by true reasons). ${ }^{7}$ Reasonable citizens have a moral right not to be coerced for reasons that they cannot in all conscience accept as sound and this right is frustrated if the reasons presented to them for some course of action that leads to their coercion are peculiar, abstruse or motivated by a conception of the good life that they do not share. The duty that each citizen has to advance only public reasons is the correlate of this moral right.

As far as Rawls is concerned, the concept of truth is divisive and stands in the way of principled agreement between reasonable citizens. Relevant to the concept of truth, citizens can reasonably disagree about the metaphysics of truth, the standards of reasoning appropriate to discover truths and about precisely which propositions about values and the good life are actually true. Under these conditions a theory of public deliberation orientated towards discovering truths is alleged by Rawls to be incapable of providing the basis of fair agreement between free and equal citizens. So the concept of truth ought to, if possible, be eliminated (Rawls 1996, p. 94; 2007, pp. 1-20). On this view, the idea of public reasonableness carries all of the weight that the concept of truth does in the kinds of argument conducted in most other spheres of life. The reasonable citizen is one who is responsive to reasonable public arguments and willing to conduct herself by the lights of reasonable argument and reasonable deliberation; reasonable legal and political

\footnotetext{
7 These are arguments that Cohen adduces in support of his conception of public reason which he takes to be a fair interpretation of Rawls's view. The first is in Cohen (1999) and the second and third are in Cohen (1993). Thomas Christiano provides a usefully succinct exposition and analysis of these arguments (Christiano 2009). Even if we accept these Rawlsian arguments, there are still considerable complications in determining how we interpret the requirement and go about restricting our set of permissibly public reasons. One way of interpreting the restrictive requirement is to say that instead of relying on controversial truth claims, justifying reasons ought to be drawn from principles consistent with one or other reasonable conception of justice. A public reason in this sense could be defined as a principled reason that can be permissibly advanced with respect of some policy or action where the principle is one that can be drawn from a reasonable conception of justice which is itself a member of the set of all reasonable conceptions of justice. All members of the set of reasonable conceptions of justice must be capable of being constructed out of the ideas characteristic of the overlapping consensus. This ensures that citizens will be arguing with each other in terms that they can both endorse even though they disagree with each other about principles and policies in a manner characteristic of political argument in a democratic society. See (Rawls 1999) especially p. 584. A different way of interpreting the requirement to say any citizen, when justifying their favoured outcome, should only advance reasons that all reasonable citizens could share given the commitments that the citizens engaged in the deliberation actually have. The two interpretations are often run together. However, there is a possible tension between the priorcommitment restriction and the more direct 'reasons all could share' restriction depending on how the second restriction is interpreted. If interpreted empirically it could be in outright conflict with prior commitment or we could interpret 'reasons all could share' as 'reasons that accord to a prior commitment to standards of reasonableness' then the second idea is subsumed by the first. I think it is fair to say that Cohen is attempting to steer a middle course although I do not think it is entirely clear precisely how the mechanics of his solution work. There are further complications depending on whether we take citizens to be deliberating from shared premises or converging towards shared justifications. The first half of Bohman and Richardson (2009) admirably illustrates the enormous complexity involved in interpreting these matters. These matters take us outside Rawlsian conceptions of public reason and since this paper is only concerned with Rawlsian conceptions of public reason I will leave these matters to one side.
} 
institutions and reasonable laws are those which are capable of being supported by reasonable arguments and are capable of drawing the reasoned endorsement of reasonable citizens (and so on).

The elimination of truth and its replacement by a conception of public reasonableness has the capacity to generate a certain amount of dissonance between the personal commitments of citizens (together with their everyday folk-deliberative means of justifying those commitments) and their duties with respect to public deliberation. However, in Rawls's version of the theory of political deliberation the duty to advance public reasons has a narrow scope and extends solely to the reasoning on matters of basic justice and constitutional essentials. So, even if the ideal of public reason looks highly revisionary Rawls can mitigate its radical appearance by limiting its application. Reasoning on matters that do not concern basic justice and the constitution does not require this sort of restriction and Rawls's view of the content of 'matters of basic justice' is sufficiently narrow to exclude a good deal of everyday political deliberation from the strictures of public reason. Since the practical reasoning of ordinary citizens will not be mobilised on every deliberative occasion they may not have to experience a dissonance between their folk-deliberative commitments and the requirements of public reason all that often. When they do it may be possible to justify the elimination of truth from their reasoning on the basis of the special features of the subject of their deliberations.

For Cohen, the possibility that public reason does not cohere with the deliberative practices of ordinary citizens is a rather more pressing concern than it is for Rawls. Cohen thinks that the requirement to adhere to the standards of public reason applies rather more widely than Rawls thinks it does. Cohen believes, unlike Rawls, that every deliberation which ends with a decision backed by the coercive force of the state possesses the kind of distributive consequences that makes it a debate about matters of basic justice. Cohen is also committed to a more expansive procedural conception of justice and democratic legitimacy. The idea here is not merely that citizens have an interest in reasonable political outcomes, but also that the act of deliberating according to the procedures of public reason expands the reasonable moral sensibilities of citizens (Cohen 1989, 2003). So, on Cohen's view, citizens deliberate from shared premises towards an outcome that is procedurally ensured to be reasonable (because of the reasonableness of its premises) and citizens additionally find and discover new reasons to endorse these shared premises and to revise their own commitments because of and by means of their deliberation with other reasonable citizens. So, on Cohen's view, there is little possibility of justifying a conception of public reasoning that is dissonant with the ordinary reasoning practices of citizens on the basis that its scope is limited or that its requirements will only apply to particular office-holders such as supreme court judges.

So, for Cohen, the elimination of truth from public reason carries a great cost since the ideals of public reasoning ought to apply to each and every instance of democratic deliberation. The elimination of truth gives the appearance of contemplating the elimination of a central item in the normative vocabulary of each citizen and denying its use to them in political argument. Cohen agrees with Rawls that arguments about the metaphysics of truth do not have any great traction in debates conducted in the forums of public reason, but Cohen does not think that 
this implies that truth has no importance in political dispute. Truth has importance since the activity of classifying propositions as true or false has a very great normative significance for any reasonable and rational deliberator. When we advance reasons as reasons for action or belief we argue in favour of reasons that we think are both relevant and true and against reasons we think irrelevant or false; this is the normative importance of truth. According to Cohen, by eliminating truth from political liberalism and public reason, Rawls has thrown the highly significant normative importance of truth out with the metaphysical bathwater. I think Cohen's worries about the elimination of truth are compelling but the pertinent question is whether it is possible to find a way of accommodating truth in public reason. The challenge is to construct a political conception of truth that is both sufficiently thin and neutral to satisfy the requirements of political liberalism but which, at the same time, genuinely satisfies the DAC. So, from this, we have two adequacy conditions for a political conception of truth: the descriptive adequacy condition and a consistency with political liberalism requirement:

A. Descriptive adequacy condition (DAC): the political conception of truth has to accommodate the folk understandings of 'mundane truth', 'the culture of truthfulness' and 'truth as the aim of deliberation'.

B. The political liberalism requirement: the political conception of truth has to be compatible with the fundamentals of political liberalism and with political constructivism (it needs to avoid asserting any theory about the nature of truth).

So, how does Joshua Cohen understand the DAC? In 'Truth and Public Reason' he represents the normative role of truth with five claims about the role of truth in practical reason (Cohen 2009, pp. 13-14).

\section{Five Claims about Truth}

Claim 1 Truth is controversial but, like concepts of cause, object, fact, reason and evidence, it is fundamental to our thought and reasoning.

Claim 2 Truth is irreducibly linked to belief and meaning. Beliefs aim at the truth, and to come to believe that a proposition is false is fatal to that belief. [Truth has a sorting function with regard to our beliefs.]

\footnotetext{
8 The conditions as Cohen states them are a little different: firstly, the conception needs to avoid asserting any theory about the nature of truth and, secondly, the conception needs to include at least the four commonplaces about truth which I discuss below (Cohen 2009, p. 26). I have modified the second condition to state that the conception needs to accommodate the considerations adduced in the five claims about truth and practical reasoning. This is a legitimate move since Cohen thinks that the four commonplaces capture what is significant about the five claims and the commonplaces are constructed from the materials contained in the five claims; that is to say, the five claims are logically prior to four commonplaces. Moreover, even if Cohen dropped the five claims and made the four commonplaces freestanding I think we could still legitimately doubt that the four commonplaces captured the standards necessary for describing how truth operates in a joint exercise of practical reasoning like a public deliberation. These issues are discussed in the next section.
} 
Claim 3 Whereas we may believe a proposition without deliberating, when we deliberate we try to come to a determination about that proposition's truth. [Deliberation aims at the truth.]

Claim 4 Truth is central to the enterprise of interpretation - the attempt to interpret someone's utterances often begins with the assumption that what they are saying is true.

Claim 5 Truth is fundamental to reasoning: 5.1: judging: judging whether $P$ is intimately connected to judging $P$ to be true; 5.2 : assertion: asserting $P$ is commonly understood to involve asserting that the content of $P$ is true; 5.3: assumption: when we assume $P$ we usually assume $P$ to be true; 5.4: reasons for belief: reasons for believing $P$ are reasons for believing $P$ to be true; 5.5: logical consequence: the special virtue of deductive argument is that it is truth-preserving; 5.6: truth is intimately and irreducibly connected with norms of thought and interaction that call for sincerity, accuracy, attentiveness and 'getting it right'.

We can call these five claims about truth Joshua Cohen's understanding of the folk conception of truth in practical deliberation. The five claims are a description of the normative importance of truth for our folk-deliberative practices. So, satisfying the DAC involves demonstrating that the political conception of truth can satisfy these five claims about truth. In order to fulfil the requirements that follow from the five claims Cohen loosely derives four commonplaces about truth which he claims will both satisfy the DAC in precisely this way and be compatible with the fundamentals of political liberalism. These four commonplaces will satisfy both the DAC and the political liberalism condition and thus be suitable materials for constructing a political conception of truth.

\section{Four Commonplaces about Truth}

Commonplace\#1 Attitudes: truth is the norm governing beliefs, assertions and judgements.

Commonplace\#2 Correspondence: true beliefs present things 'as they are'although the commonplace is neutral in respect of the various metaphysical stories one could tell about what there is and the relationship between propositions and (e.g.) a realm of mindindependent facts.

Commonplace\#3 Contrast: there is a distinction between truth and warrant or justification-but the commonplace is neutral on the question as to whether truth is a substantive property different from warrant, and it does not offer an account of what distinguishes it from warrant, and, Cohen tells us, that it will also avoid claiming that nothing informative can be said on this issue.

Commonplace\#4 Value: '...Truth is important; and, given that truth is different from warrant, that truth is important in a way different from the way that warrant is important.' (Cohen 2009, p. 27) 
Cohen contends that whereas there is no theoretically substantial concept of truth available in public reason 'true', understood in this way, is an available tag which goes proxy for the substantial concepts of truth in comprehensive philosophical and moral doctrines. The four commonplaces about truth represent an overlapping consensus on truth and its importance and that, as far as Cohen is concerned, is all that is required. ${ }^{9}$ On this account we can have the political conception of truth, and allow truth-talk in public deliberation, while jettisoning worries about the metaphysics of truth and without having to make substantive claims about the truth of comprehensive ideas of the good which would conflict with the burdens of judgement. Additionally, just so long as they adduce public reasons in so doing, citizens can permissibly affirm that they believe in the truth of those public considerations for deeper reasons in their comprehensive ideas of the good life that they also believe to be true. So, two citizens may agree and utter 'that- $P$ is true' at the same time as disagreeing entirely about the criteria that would make 'that- $P$ ' true. Yet these two citizens will agree that they place great normative importance on 'that- $P$ ' being true and this importance is represented by their agreement on the four commonplaces. ${ }^{10}$

There are, however, some omissions and ambiguities in Cohen's derivation of the four commonplaces about truth from his five claims about truth. There is nothing, on Cohen's four commonplaces view, to constrain either of our citizens to see the truth of 'that- $P$ ' as being thought or action guiding in any particular specified way. Truth will, as the norm governing beliefs, assertions and judgements, influence these items in some unspecified way (and by Commonplace\#3, in a way different from warrant

\footnotetext{
9 As Cohen puts it, 'I will defend two conclusion about [the] role [of truth]...First, the concept of truth, and judgements and assertions that apply the concept to basic principles of justice... have a legitimate role to play in public, political argument...Second, the conception of truth that plays a role in public justification should be political...By a political conception of truth...I mean...a set of claims about truth-for example, that truth is distinct from warrant, and that it is important-that it is suited for the purposes of political reflection and argument in a pluralistic democracy, characterised by doctrinal disagreements...the aim is to present a view of truth that suffices for public reasoning and could reasonably be endorsed by the adherents of conflicting doctrines, which may themselves employ richer conceptions of truth...A political conception of truth is thus a genuine conception of truth...' (Cohen 2009 , p. 3) '... [the political conception of truth] is classified as political because it can reasonably be endorsed as common ground for the purposes of consequential collective decisions.' (Cohen 2009, p. 6).

10 The folk-deliberative importance of truth for a deliberator is that she wants her reasons-for-belief and reasons-for-action not to be false. The point of deliberation on the folk view is to come to true reasons for belief and action. It might be objected that the way in which people generally express their commitments gives us a reason to doubt that people care about truth in quite this sort of way. For example, someone might say 'Jesus is Lord' rather than 'Jesus is Lord is true'. However, this person, if sincere, is still strongly committed to the truth of the claim insofar as the belief-guiding or action-guiding qualities of the claim depend on its truth. So even if they just say (with suitable emphasis) 'Jesus is Lord!' they will take this statement to be true in the sense that the proposition corresponds to an independent reality and is not merely reasonable or warrantedly assertable. The truth of the claim is operative for them, they will think that it is true in such a way that it excludes its negation and that if the statement could be shown to be false then they would no longer have any reason to believe or act upon it. In fact there will be a complex of disputable claims involved in the apparently simple 'Jesus is Lord!' statement. It is likely to encompass straightforward claims of factual truth: 'Jesus exists'; 'Jesus's Lordship has been proclaimed (by a suitable authority)'; and so on. As well as some rather more complex value truth claims: 'The authoritative Lordship of Jesus provides reasons for us (all?) to $\varphi$ '; 'Christ's conduct provides a model example for the ideally good life' and so on.
} 
which may have some other unspecified influence). Cohen is also unclear as to whether such specific formulations as 'beliefs aim at the truth, and to come to believe that a proposition is false is fatal to that belief' (Claim 2) fall within the scope of the commonplace formulations like 'truth is the norm governing beliefs, assertions and judgements' (Commonplace\#1) in such a way that this specific formulation is meant to exclude rival specific formulations. Also missing from both the five claims and the four commonplaces are some important features of ordinary practical reason such as 'to believe that the reasons in favour of action are false, in the absence of other reasons that one believes to be true, is to no longer have good reasons for that action'. To sharpen up these indeterminacies and remedy these omissions is of course to say something more substantial about truth and risks violating the consistency with political liberalism condition.

Setting that worry aside for the moment, how does Cohen's political conception of truth work in a case of deliberative disagreement? If we take the example of a group of citizens arguing about whether or not someone has an obligation to a third party we can see this more clearly. So when John says 'A has an obligation to B' and Peter objects and says 'A has no such obligation', Cohen thinks that it is fine for John to then say, 'but the reasons in favour of the view that A has an obligation to B are true'. However, in terms of how this declaration operates in public reason, this has no more force than the simple declaration 'there are reasons in support of the view that A has an obligation to B' (similarly with Peter's assertion of the falsity of the reasons adduced in favour of the obligation in dispute). Where recognising truth, and allowing it to appear in such declarations, makes a difference is in allowing Peter and John to express their, perhaps, deeper commitments to the truth of their beliefs by making it possible for these to be recognised in the deliberative forum (a commitment to truth which they both share in common despite sharing neither the same commitment in terms of their deeper beliefs about the nature of truth nor their beliefs about what is true). In essence, it allows John and Peter to express the fact that they disagree because they both think that what they are saying is true. However, truth has no decisive, operative role in their disagreement. The analysis of the permissibility of the terms of their dispute will instead focus on each one's attempt to persuade the other that their position is the most reasonable. If John's claim cannot be cashed-out in terms of its reasonableness then it will not permissibly count and Peter's claim, assuming that it can be cashed-out in terms of its reasonableness, will win out. If both claims are reasonable in this sense, and neither Peter nor John (or the groups of citizens that they represent) are persuaded by the other's case, then we will have to take a vote or flip a coin to break the deadlock. In neither case does truth actually do any work. This is enough to plausibly say that public reason can accommodate truthtalk, satisfying the political liberalism requirement for a political conception of truth.

I agree with Cohen that the rather ambiguous formulations of the four commonplaces about truth enable them to be the focus of agreement between citizens, and that this allows him to satisfy the political liberalism requirement. However, the cost of satisfying the political liberalism requirement may be to violate the DAC which accords truth the rather more substantial role that it plays in the five claims about truth. So why does Cohen weaken the political conception of truth in this way? The source of the problem lies in the necessary concessions that 
Cohen makes in order to head off the Rawlsian objection that truth-talk of any sort is divisive in such a way as to defeat the purposes of public reasonableness. Cohen asserts that any potential for divisiveness can be defused just so long as people accept that truth alone is not enough to make a reason suitably public. The singularity and exclusiveness of truth is only a problem if we think that because a conception of the good is true then it alone has a role to play in public reason, and Cohen thinks that we can resist the slide from the singularity of truth to conflict about the truth by accepting that truth is not sufficient to render a reason suitably public. On one level this looks like a pretty obvious move since we might require some other condition such as relevance. Some reason $R$ might be true but it may also be irrelevant to $P$. $R$ 's truth does not suffice to show $R$ 's relevance and unless $R$ is relevant to $P$ then $R$ 's truth is not sufficient to count as a reason for $P$.

One way of beefing up the role of truth in public reason would be to include truth and make reasonableness and truth jointly necessary and sufficient for making a reason count in the deliberative forum. However, Cohen rejects this move and affirms the absolute priority of reasonableness. So he says:

It makes perfectly good sense to say, 'my view is true, but other views, while not true, are reasonable to believe, and what matters for democracy's public reason is reasonableness not truth'. We need not drop the concept of truth in order to drop the thesis ... that the truth of a proposition is a necessary condition for its playing a permissible role in public reason, or the thesis ... that its truth suffices to license appeal to it in political reflection and argument. (Cohen 2009, p. 31)

Cohen makes it clear that he thinks that only publicly reasonable propositions are relevant, so, we can say that the public-reasonableness of $R$ is a necessary condition of its relevance to $P$ in public deliberation and it follows, on this view, that the publicreasonableness of $R$ is, on its own, both necessary and sufficient for a reason to count.

So, where does all of this get us? I argue that three related consequences follow from this way of understanding the political conception of truth. Firstly, we have to accept that even though truth-talk is present in public reason this conception of truth is expressive rather than operative in our deliberations. An operative conception of truth has a sorting function with respect to our judgements (compare the second of Cohen's five claims about truth): if we judge that 'that- $P$ ' is true (and relevant) then it counts, and if we judge that 'that- $P$ ' is false, then it does not. The political conception of truth does not have any kind of sorting function when it comes to deciding which reasons count; its function is to express the importance that citizens accord to truth, and so the political conception of truth is an expressive and nonoperative conception of truth (the operative and sorting role being played by reasonableness). Secondly, (just like on Rawls's view) the set of permissible public reason considerations will be a much smaller subset of the set of ordinarily folkrelevant considerations. Since reasonableness performs the sorting function in the deliberation there will remain a number of relevant and true yet unreasonable

\footnotetext{
11 My emphasis. Cohen is, for his purposes, right to reject making truth necessary since such a move is bound to violate the political liberalism condition for the adequacy of a political conception of truth.
} 
considerations to which it would be impermissible to appeal. Thirdly, (just like on Rawls's view) the subset of permissible considerations will also comprise not only true considerations but also, possibly, a good number of false ones as well.

For Cohen, truth is important because recognising the importance of truth is required in order to show respect to citizens' commitment to the truth, and truth's inclusion is part and parcel of showing equal respect and concern to citizens and the seriousness with which they take their commitments. There is some appeal in the view when we think about it like this. It seems to do justice both to our intuitions about taking people's reasonable views into account and to some of the importance that people attach to thinking that their judgements are true. However, it only does partial justice to the latter consideration. The political conception of truth may satisfy thin expressive and recognitional requirements since the conception recognises citizens as people who care about truth. However, it fails to capture the deeper normative importance of an orientation towards truth that Cohen sets out in his five claims about truth. The four commonplaces about truth out of which the political conception of truth is constructed are an inadequate explication of the five claims about truth which are far more substantial. So, whereas Cohen can satisfy the political liberalism requirement for his conception of truth by making the political conception of truth suitably thin and expressive, he does so at the cost of failing to satisfy the DAC by rendering up a conception of truth that is far too weak to capture the role that truth plays in ordinary political deliberation. I contend that that it is the more substantial conception of truth that drives the intuitive plausibility of Cohen's concerns about the exclusion of truth but that the requirement to make truth compatible with political liberalism excludes any conception of truth capable of satisfying those concerns. In order to show why this is the case I now go on to consider the problem of false yet reasonable justifications; a problem to which Cohen's conception is just as vulnerable as Rawls's.

\section{The Inadequacy of the Political Conception of Truth}

On Cohen's view, truth is not necessary for a proposition to count as a permissible justification in public reason whereas, on the folk conception of practical reasoning, truth is a necessary condition for a proffered reason to count as a genuine reason for action or belief. ${ }^{12}$ On the folk conception of deliberation truth has a sorting function-it separates out reasons that could count from reasons that could never count. This sorting feature is present in the second of Cohen's five claims about truth. However, Cohen's political conception of truth does not have a sorting function since the sorting function is catered for by the political conception of

\footnotetext{
${ }^{12}$ I follow Parfit here in distinguishing between normative reasons from motivating reasons. $R$ only counts as a normative reason to $\varphi$ if it is true that $R$ is a reason to $\varphi$. If it is false that $R$ is a reason to $\varphi$ and $A$ performs the action $\varphi$ falsely believing that $R$ was a normative reason, if $R$ was his motivating reason, then it follows that $A$ had only a motivating reason and not the normative reason that he thought he had. Clearly, what we are interested in for the purposes of this paper, given that we are interested in what sorts of reasons can stand as a justification for $\varphi$-ing, are normative and not motivating reasons. A very detailed discussion of this distinction can be found in (Parfit 1997) and in the first part of (Parfit 2011).
} 
reasonableness; reasonable propositions may count, unreasonable propositions can never count.

A publicly reasonable proposition adduced for or against some item of public deliberation can be a principled proposition where the principle in question is taken from one of the multitude of reasonable conceptions of justice. So, among the multitude of reasonable conceptions of justice there will be conceptions that contain or generate reasons that are false (perhaps even false and obnoxious). ${ }^{13}$ An alternative way of understanding the reasonableness requirement is to say that we can only permissibly adduce reasons that could be acceptable as reasons for action by citizens (taken as they are) who are reasonable because they are committed to the democratic procedure and the attempt to deliberate towards a consensus. Among the set of reasons sanctioned by this latter view there will also be a good many reasons that are technically reasonable yet false. The upshot, on either view of the requirement of reasonableness, and as Joseph Raz has pointed out ( $\operatorname{Raz} 1998$ ), is that we have to regard false reasons, and even very obviously false reasons, as quite capable of providing the requisite public justifications.

If false yet reasonable reasons are admissible in public reason and the outcomes of democratic deliberations (laws or policies) that adhere to the requirements of public reason have legitimacy then two things follow: first, we have to accept that coercive laws and policies are capable of being justified by sincerely believed falsehoods. Second, since we allow that reasonable people can object to principles, laws and policies based on those beliefs, we have to allow that false beliefs are able to legitimately modify the content of laws and policies and that true reasons can be rejected on the basis of false yet reasonable beliefs. It is plausible to assume that people are quite often motivated to act and to offer up justifications for their views on the basis of false reasons. ${ }^{14}$ However, it is quite another thing to think that these false reasons actually do real work in justifying the outcomes of public deliberation. And whereas it is not hard to accept that we may be legitimately coerced for reasons that are less than fully vindicated as true, ${ }^{15}$ it is harder to accept that we ought to rationally assent to falsehoods where we are sure that we can identify true alternative justifications (either for the same or for different outcomes).

So, let us consider an example: one feature of the political liberalism shared by both Rawls and Cohen is that reasonableness requires that each and every justice-

\footnotetext{
${ }^{13}$ Rawls discusses the plurality of reasonable conceptions of justice and some of the conditions that they will have to meet as a condition of their reasonableness in the introduction to (Rawls 1996). The materials out of which the set of reasonable conceptions justice are constructed allows for a fairly open and diverse set, and the minimal list alongside the construction rules in no way guarantees the absence of a number of reasonable yet obnoxious conceptions of justice. That some of these conceptions will be false is guaranteed if at least some elements of the content of any of these conceptions are truth-apt since at least some of these conceptions have competitive and exclusive content.

${ }^{14}$ False reasons may be believed to be true sincerely (either through error or non-blameworthy ignorance) or they may be the product of self-delusion or irrationality. None of this would be sufficient on its own to make the agent unreasonable.

15 This may be because either the truth is not forthcoming and some sort of decision has to be made or the decision is made on the basis of a procedure that we regard as legitimate. On the other hand it may be because there are sound pragmatic reasons for settling on something that, whereas not strictly true, is the best that may be achieved given the circumstances.
} 
relevant deliberation must be strictly neutral with regard to the comprehensive disagreement among citizens on whether objects have intrinsic value or which objects have intrinsic value. So, advancing reasons based on the following principle would be ruled out as unreasonable on the Rawls-Cohen view:

If some object or institution has existed for a long time then it ought to be preserved or at least not interfered with unless there are strongly compelling reasons for doing so (e.g. it is for some reason deeply unjust not to interfere with it). ${ }^{16}$ It would be unjust, without compelling reasons, to interfere with the object or institution since the object's age carries with it a presumption of its intrinsic value. ${ }^{17}$

Let us call this 'the principle of the presumptive value of old stuff'. The principle could figure in a reasonable doctrine of the good life (a way of life committed to the preservation of old things)_but it could not figure in any politically liberal conception of justice, and it could not be advanced as a public reason since it makes claims about the intrinsic value of things other than persons about which there is bound to be reasonable disagreement.

So, imagine a proposal to demolish the famous standing stones at Stonehenge in order to build a hospital. Let us also assume that the stone circle has an owner who is not adverse to its demolition and that the hospital would have great utility for the people of Wiltshire, and that we could build a hospital nearby without demolishing the stones but that it would cost a good deal more. I take it that it is true that the stones are connected to an interesting history (even if that history is somewhat opaque), that they have a certain majesty in their surroundings and that there is something deeply impressive about objects of that age (even if that something is rather ineffable). And, moreover, even though the people that constructed the stone circle are long dead, and there is no possibility of violating their rights, there is something crassly philistine about casually destroying something that those people took such pains to build.

Cohen could say that his view of public reason can accommodate the fact that people value the stone circle, and that this valuing has weight in the deliberation since the interests of these citizens cannot simply be dismissed or over-ridden. Moreover, public reason can accommodate the fact that people strongly believe that their valuations are true. However, the more general truth or falsity about the intrinsic value of Stonehenge could not figure operatively in Cohen's public deliberation. In ordinary deliberation, or at least in the folk understanding of such deliberation, the point and purpose of the debate would cluster around arguments about whether: (i) the principle was sound; and (ii) (depending on whether (i) could be vindicated) whether the stones fall under the principle; and (iii) (depending on whether (i) and (ii) could be vindicated) whether the reasons for preservation were weightier than any of the other considerations at play. The problem is that the

\footnotetext{
${ }^{16}$ We could add other qualifying clauses to the antecedent-e.g. 'is connected with an interesting or important history', or 'is part of some past culture', or 'was created by an interesting or important person'.

17 This principle is an inference from a more fundamental principle that one ought not to interfere with or cause harm to things that are intrinsically valuable together with an additional premise asserting the (presumptive) intrinsic value of old objects.
} 
reasons that figure in Cohen's public reason version of the debate are far narrower and weaker than the reasons that the folk conception which provides the ordinarily intelligible backdrop to the case. At the very least, the ordinary way of envisaging a deliberation on this case is that it is in part concerned to establish whether it is indeed true that the stone circle has intrinsic value and is worthy of preservation. That is to say, we are more concerned to work out whether Stonehenge is truly of a value sufficient to outweigh the disadvantages of building the hospital elsewhere and not with the more mundane question of establishing how many people, as a matter of contingent fact, happen to value it.

However, on Cohen's view, if a number of people express the reasonable (yet probably false) objection that they do not see any reason why they ought to subsidise the more expensive option given that they have no interest in stone circles $^{18}$ then we could have no further recourse to the ordinary view of our deliberation. The reasonable yet probably false objection shows that this issue involves a disagreement that falls under the constraints of reasonable disagreement and the burdens of judgement. Our defence of Stonehenge can no longer rely on the kinds of substantial reasons characteristic of the intelligible background to our case on the ordinary view of the deliberation. Instead, our defence has to rely on fairly weak reasons such as ' $W e$ value these things-even though you do not (and we will not gainsay your refusal to value these things) — and the demolition of Stonehenge would remove from our lives something that we value greatly'. The fact that some people have a strong preference for keeping the stones may win out in the battle for achieving consensus and, to be sure, Cohen's view would suggest that citizens would not be treated as free equals if their expressed preferences were not taken into account. However, the point is that victory or defeat for the defenders of the stones would not turn on the soundness or validity of arguments for the value of the stones (and the weightiness of that value) but on the balance and force of the expressed preferences in the deliberative community.

For Cohen, truth is important because recognising the importance of truth is required in order to show respect to citizens' commitment to the truth. This is an appealing view: it seems to do justice both to our intuitions about taking people's reasonable views into account and to some of the importance that people attach to thinking that their judgements are true. However, it only does partial justice to the latter consideration; citizens generally care about the truth precisely because, among other things, they care about the adequacy of the reasons that are advanced in public deliberation. They care that both they and their representatives are acting for genuine reasons and it is a condition for acting on a genuine reason that that reason be true. That, at least, is the folk view of public deliberation. The political conception of truth may satisfy thin expressive and recognitional requirements since the conception recognises citizens as people who care about truth. However, it fails to capture the deeper normative importance of an orientation towards truth that Cohen sets out in his five claims about truth. The four commonplaces about truth out

\footnotetext{
18 Probably false insofar as it does not follow from the fact that I do not value $V$ myself that $V$ is not valuable or that there is no reason for me to value $V$. Nor does it follow from the fact that I find no value in $V$ that $\mathrm{I}$ have no duties with respect to $V$ 's preservation.
} 
of which the political conception of truth is constructed are an inadequate explication of the five claims about truth which are far more substantial. So, whereas Cohen can satisfy the first of the adequacy conditions for his conception of truth by rendering it compatible with political liberalism, I argue that he does so at the cost of failing to satisfy the DAC by rendering up a conception of truth that is far too weak to capture the role that truth plays in ordinary political deliberation. My argument is that it is the more substantial conception of truth that drives the intuitive plausibility of Cohen's concerns with the exclusion of truth, but that the second adequacy condition excludes any conception of truth capable of satisfying those concerns.

These considerations ought, I argue, to cast doubt on the persuasiveness of the case for a political conception of truth and the compatibilist claim that we can have both Rawlsian public reason and truth at the same time. If we recall the two adequacy conditions for a political conception of truth:

A. DAC: the political conception of truth has to accommodate the folk understandings of 'mundane truth', 'the culture of truthfulness' and 'truth as the aim of deliberation'.

B. The political liberalism requirement: the political conception of truth has to be compatible with the fundamentals of political liberalism and with political constructivism (it needs to avoid asserting any theory about the nature of truth).

I contend that in accommodating the political liberalism requirement Cohen fails to satisfy the DAC. In order to satisfy the DAC our account of public reason has to accommodate 'mundane truth', 'the culture of truthfulness' and 'truth as the aim of deliberation'. Recall that the motivation for satisfying the DAC is to show that Rawlsian public reason is not excessively revisionary. Any account that fails to satisfy the DAC does not sit comfortably on the middle ground of the descriptiverevisionary continuum and is excessively revisionary. Cohen's political conception of truth can satisfy the mundane role of truth and the culture of truthfulness requirements, but it does not satisfy the 'aim of deliberation' requirement that features in the second and third of his five claims about truth. So, if we take the basic task to be the construction of a conception of public deliberation that sits comfortably in the middle-ground of the descriptive-revisionary continuum, we can reconstruct Cohen's argument against Rawls as follows:

1. Any theory of public deliberation that does not satisfy the DAC is an excessively revisionary theory of deliberation.

2. The DAC requires that the theory of public deliberation accurately captures our folk conception of public deliberation which takes truth as centrally important (this is the point of Cohen's 'five claims about truth').

3. Therefore any theory that eliminates truth cannot satisfy the DAC.

4. Rawls's theory eliminates truth.

5. Therefore Rawls's theory of deliberation cannot satisfy the DAC since truth is wholly absent from his deliberative procedure and his is therefore an excessively revisionary theory of public deliberation. 
Cohen thinks that Rawls's account cannot stand on its own as an adequate theory of public deliberation because it is an excessively revisionary theory. Cohen wants to say that his theory, on the other hand, is not excessively revisionary because it can accommodate our folk concern with truth. However, we can turn Cohen's own premises against his conclusion to show that Cohen's deliberative procedure is just as revisionary as Rawls's:

6. Any conception of truth that is capable of satisfying the DAC will employ the 'aiming at truth' requirement in a manner in which truth is operative rather than merely expressive where we exclude false reasons as non-operative in our justifications (Cohen affirms this view in the first, second and third of his claims about truth).

7. Cohen's political conception of truth does not exclude false reasons and it regards truth in public deliberation as expressive rather than operative; it lacks the sorting function that Cohen thinks is required in his second claim about truth.

8. Therefore Cohen's political conception of truth cannot satisfy the DAC.

9. Therefore, Joshua Cohen has, just like Rawls, an excessively revisionary theory of public deliberation.

\section{Conclusion}

The political conception of truth may satisfy the political liberalism requirement but, in so doing, it fails to satisfy the DAC, and on this basis we can say that Cohen's conception of public deliberation is excessively revisionary. Moreover, I do not think that this is a contingent failure. If we strengthen the conception of truth to a level sufficient to satisfy the DAC we are of necessity going to fail to satisfy the political liberalism requirement. On this basis I think it is also fair to say that we have good reason to think that truth and Rawlsian public reason really are incompatible.

Open Access This article is distributed under the terms of the Creative Commons Attribution 4.0 International License (http://creativecommons.org/licenses/by/4.0/), which permits unrestricted use, distribution, and reproduction in any medium, provided you give appropriate credit to the original author(s) and the source, provide a link to the Creative Commons license, and indicate if changes were made.

\section{References}

Bohman, James, and Henry Richardson. 2009. Liberalism, deliberative democracy, and 'reasons that all can accept'. Journal of Political Philosophy 17: 253-274.

Christiano, Thomas. 2009. Must democracy be reasonable? Canadian Journal of Philosophy 39: 1-34.

Cohen, Gerald. 2008. Rescuing justice and equality. Cambridge, MA: Harvard University Press.

Cohen, Joshua. 1989. Deliberation and democratic legitimacy. In The good polity, ed. Alan Hamlin and Philip Pettit, 17-34. Oxford: Blackwell. 
Cohen, Joshua. 1993. Moral pluralism and political consensus. In The idea of democracy, ed. David Copp, Jean Hampton and John E. Roemer, 270-292. Cambridge: Cambridge University Press.

Cohen, Joshua. 1997. The arc of the moral universe. Philosophy and Public Affairs 26(2): 91-134.

Cohen, Joshua. 1999. Reflections on Habermas on democracy. Ratio Juris 12: 385-416.

Cohen, Joshua. 2003. For a democratic society. In The Cambridge companion to Rawls, ed. Samuel Freeman, 86-138. Cambridge: Cambridge University Press.

Cohen, Joshua. 2009. Truth and public reason. Philosophy and Public Affairs 37(1): 1-42.

Estlund, David. 1998. The insularity of the reasonable: Why political liberalism must admit the truth. Ethics 108: 252-275.

Freeman, Samuel. 2003. The idea of public reason revisited: Public reason and political justifications. Fordham Law Review 72: 2021-2072.

Parfit, Derek. 1997. Reasons and motivation. Aristotelian Society Supplementary 71: 99-130.

Parfit, Derek. 2011. On what matters, vol. 1. Oxford: Oxford University Press.

Quong, Jonathan. 2011. Liberalism without perfection. Oxford: Oxford University Press.

Rawls, John. 1996. Political liberalism. New York, NY: Columbia University Press.

Rawls, John. 1999. The idea of public reason revisited. In John Rawls: Collected papers, ed. Samuel Freeman, 573-615. Cambridge, MA: Harvard University Press.

Rawls, John. 2007. Remarks on political philosophy. In John Rawls: Lectures on the history of political philosophy, ed. Samuel Freeman, 1-20. Cambridge, MA: Harvard Belknap.

Raz, Joseph. 1994. Facing diversity: The case of epistemic abstinence. In Ethics in the public domain: Essays in the morality of law and politics. 60-96. Oxford: Oxford University Press.

Raz, Joseph. 1998. Disagreement in politics. The American Journal of Jurisprudence 43: 25-52.

Strawson, Peter. 1959. Individuals: An essay in descriptive metaphysics. London: Methuen and Co. 